\title{
O Século das Luzes e o medo do escuro - a fantasia na Antropologia de Kant'
}

\author{
Luís Fernandes dos Santos Nascimento
}

UFSCAR

1 Artigo escrito com o apoio do Capes-Cofecub SH 754-12. 

Pensemos em um espaço, em um gabinete ou quarto completamente escuro (a dark room) que só começará a ser iluminado à medida que for preenchido ou mobiliado (furnished). Essa imagem, que conjuga luzes e trevas, é apresentada no Ensaio sobre o entendimento humano, de John Locke ${ }^{2}$, para descrever o estado primitivo ou originário do entendimento. Partir da escuridão, do momento em que a mente ainda não começou a conhecer e que não tem qualquer ideia, é próprio de uma postura experimental pela qual não se aceita nenhuma verdade prévia, atitude que se caracteriza por observar e descrever a ação do entendimento e evitar o risco de cair em noções vagas ou preconceitos que apenas atrapalhariam a compreensão do modo como as trevas são dissipadas ou da maneira com que o quarto escuro é iluminado. Locke recorre à legitimidade da observação e da experiência: “a melhor via para se chegar à verdade está em examinar as coisas tal como são e não em concluir que são tal como as fantasiamos (as we fancy of ourselves) ou como os outros têm nos ensinado a imaginar (or have been taught by others to imagine)" (Locke, 1952, p. 147). Essa concepção de um conhecimento progressivo, que se desenvolve sem servir-se de verdades estabelecidas e que privilegia a análise e a observação, é exaltada por grandes nomes do pensamento das Luzes, como D’Alembert, em seu Discurso

1 Diderot, 2000, p. 177.

2 A passagem do Ensaio do entendimento humano que apresenta a mente ou o entendimento como sendo um quarto escuro está no Livro II, Capítulo XI, Parágrafo 17 da referida obra. Neste parágrago, cujo título é Dark room, se lê: "For, methinks, the undestanding is not much unlike a closet wholly shut from light, with only some little openings left, to let in external visible resemblances, or ideas of things without: would the pictures coming into such a dark room but stay there, and lie so orderly as to be found upon occasion, it would very much resemble the understanding of man, in reference to all objects of sight, and about them." (Locke, 1952, p. 147). No Capítulo I do mesmo Livro II, parágrafo 2, uma imagem similar já havia sido apresenta. Neste caso, a mente é comparada a um papel em branco ("White paper, void of characters, whitout any ideas") que apenas é preenchido com a experiência (Locke, 1952, p. 121). 
Preliminar à Enciclopédia, e Voltaire, que na décima terceira de suas Cartas inglesas afirma o seguinte acerca do filósofo britânico:

Locke desenvolveu a razão humana para o homem, como um excelente anatomista explica as molas do corpo humano. Apoia-se no archote da física; algumas vezes ousa falar afirmativamente, mas também ousa duvidar. Em vez de definir de um só golpe aquilo que não conhecemos, examina por graus aquilo que queremos conhecer. Toma uma criança no momento de seu nascimento; segue passo a passo os progressos de seu entendimento; vê o que possui em comum com os animais e o que possui acima deles; consulta o próprio testemunho, isto é, a consciência de seu pensamento (Voltaire, 1973, p. 27).

Como mostra essa passagem de Voltaire, a imagem da criança é de fundamental importância para Locke: a ela o autor inglês recorre muitas vezes quando deseja explicar o modo como o entendimento opera: como chegamos às ideias e como delas nasce a linguagem. Também é a criança - ou, antes, certa noção de infantilidade e imaturidade - que surge no texto de Locke quando se discute alguns desvios ou problemas que impedem ou atrapalham o bom funcionamento da mente. As passagens dedicadas ao engenho (wit) e à loucura, por exemplo, nos mostram um uso das próprias faculdades que podem causar confusão e, no lugar de iluminar, podem obscurecer a mente. O engenho é um modo de reunir e combinar ideias de maneira variada e rápida, sem que se possa compreender ou reconstituir com exatidão o caminho que se percorreu, isto é: as ideias são reunidas sem nenhuma razão aparente. Esse procedimento é típico de uma mente imaginativa e criadora, capaz de compor aqueles gracejos ou zombarias (pleasantry) "que tocam de maneira tão vívida a fantasia e, por isso, são tão aceitos por toda gente, pois sua beleza aparece à primeira vista e não requer qualquer esforço do pensamento para examinar que verdade ou razão há nela” (Locke, 1952, p. 144). Essa beleza que tanto encanta nada tem de verdadeiro e pode ser prejudicial 
ao conhecimento: "homens dotados de engenho e pronta memória", diz-nos Locke, "nem sempre têm o juízo mais claro e a razão mais profunda” (Ibid., p. 144). A vivacidade do engenho antes confunde do que esclarece, diz mais respeito às paixões e à fantasia do que à razão e à verdade. Homens que se pautam por esse tipo fantasista de associação de ideias podem se tornar loucos. A loucura, afirma o filósofo britânico, não é uma ausência de racionalidade, mas um tipo de razão desregrada que toma as fantasias por realidades. Admite-se que existe certa lógica nos raciocínios dos loucos (madmen); o problema está no princípio equivocado com que reúnem e ordenam suas ideias. Assim, um homem que se imagina rei (fancying himself a king), exigirá todo o respeito e a obediência adequados à posição que fantasia possuir. Outro que crê ser feito de vidro tomará as precauções que sua delicada e imaginária condição exige. Locke reconhece uma razão nesses dois casos, embora ela esteja sendo orientada por uma forte e poderosa imaginação: "Pois, pela violência de suas imaginações, tendo eles tomado suas fantasias por realidades, fazem deduções corretas a partir delas" (Ibid., p. 146). Um exemplo, extraído de outra obra de Locke, também é bastante ilustrativo desses momentos em que homens perdem a razão e, nesse sentido, parecem agir como meras crianças. Trata-se de um trecho de Some thoughts concerning education, passagem em que o filósofo britânico atenta para o perigo que uma imaginação descontrolada pode representar para a vida de um homem:

É o perigo ao qual o jovem é exposto pela imprudência dos criados cujo método ordinário é o de assustar as crianças e assegurar sua obediência lhes falando de lobisomens, de cadáveres sangrentos e de outros fantasmas cujos nomes suscitam a ideia de algo terrível e perigoso, dos quais têm razão de terem medo quando estão sozinhos e, sobretudo, no escuro. Previnamos esse perigo: pois embora esse meio absurdo possa impedir algumas pequenas faltas, o remédio é certamente pior que o mal (Id., 1992, p. 187). 
Uma vez introduzido em uma criança, o medo do escuro dificilmente a abandonará. Sua imaginação criará os mais diferentes fantasmas diante dos quais estará indefesa. No lugar da luz, sua mente se acostumará a produzir confusão e obscuridade. Não é difícil supor que um homem assim criado acabe por se tornar débil frente ao poder de uma fantasia criadora, e que possa até mesmo enlouquecer. Por isso, é preciso pensar em uma educação que desde o início o ajude a manter sua imaginação sob controle. Em nota à passagem de Some thoughts concerning education que citamos acima, o tradutor francês desta obra nos lembra que um argumento similar ao aqui exposto por Locke aparecerá anos mais tarde no Livro II do Emílio. Embora critique o inglês e seu modo de pensar a educação ${ }^{3}$, Rousseau concorda com este quando chama a atenção para os perigos que a imaginação e o medo do escuro podem causar para homens de todas as idades:

A noite espanta naturalmente os homens, e às vezes os animais. A razão, os conhecimentos, o espírito, a coragem libertam poucas pessoas desse tributo. Vi pensadores, espíritos fortes, filósofos, militares intrépidos à luz do dia que à noite, ao barulho de uma folha de árvore, tremiam como mulheres. Atribuímos esse pavor aos contos das babás; enganamo-nos, ele tem uma causa natural. Qual é essa causa? A mesma que torna os surdos desconfiados e o povo supersticioso: a ignorância das coisas que nos rodeiam e do que se passa ao nosso redor (Rousseau, 1999, p. 154).

3 É o que diz Rousseau no Livro II do Emílio: "Raciocinar com as crianças era a grande máxima de Locke. É a mais em moda hoje. Se sucesso, todavia, não me parece capaz de dar-lhe algum crédito. De minha parte, não vejo nada de mais tolo do que essas crianças com quem tanto se raciocinou. De todas as faculdades do homem, a razão, que não é, por assim dizer, senão um composto de todas as outras, é a que se desenvolve com mais dificuldade e mais tardiamente, e é ela que se pretende utilizar para desenvolver as primeiras! A obra-prima de uma boa educação é formar um homem razoável, e pretende-se educar uma criança pela razão! Isso é começar pelo fim, é da obra querer fazer o instrumento!" (Rousseau, 1999, p. 84). 
Signo do desconhecido, o escuro aguça a imaginação que, a partir dele, produz as mais terríveis visões. Como em Locke, reconhece-se nessa faculdade a fonte do descontrole que pode levar ao delírio e à loucura. A imaginação é naturalmente propensa ao desregramento e, por isso, merece toda a nossa atenção. Por outro lado, quando bem dirigida, ela pode ser bastante útil e fornecer à razão as imagens que necessita para desenvolver-se e conhecer. Daí a necessidade de aprender a regrar a imaginação e encontrar meios de minimizar sua força ou poder. "Descoberta a causa do mal", escreve Rousseau, "descobre-se o remédio. Em todas as coisas, o hábito mata a imaginação; só os objetos novos a despertam" (Ibid., p. 156). Trata-se então de fazer com que aquilo que normalmente surge como surpreendente e extraordinário se apresente como comum. Assim, se é o medo do escuro que aflige os homens, é preciso que encontremos meios de tornar o escuro tão banal quanto agradável. É necessário acostumar as crianças às brincadeiras noturnas, de tal modo a não mais se assustarem com as trevas e até mesmo associá-las à ideia de diversão. Rousseau propõe então jogos que devem ser feitos durante a noite: "Muitas brincadeiras à noite. Isso é mais importante do que parece" (Rousseau, 1999, p. 154). Brincar no escuro é jogar com a imaginação, estabelecer com ela um tipo de diálogo que permite encontrar uma medida adequada para a sua atuação, é o meio de fazer com que os homens se defendam das "imaginações fantásticas" (Ibid., p. 156$)$.

De modo geral, podemos dizer que quando autores como Rousseau e Locke tratam do tema da fantasia e dos poderes da imaginação o que está em questão são limites da razão e as fronteiras que a separam da desrazão, isto é: o embate entre luzes e trevas. Não são poucos os filósofos do século XVIII que se dedicaram ao tema. Pensemos em Lord Kames e no seu ensaio Temor dos 
poderes sobrenaturais na escuridão $0^{4}$ ou na seção sobre a Obscuridade que Edmund Burke escreve para a sua Investigação filosófica sobre a origem de nossas ideias do sublime e do belo. Na origem de todo misticismo, pavor ou loucura, encontramos o tema da imaginação desregrada, criadora de fantasmas. Burke, por exemplo, nos lembra que ao proteger o tirano da vista e do contato com o seu povo, os governos despóticos estimulam em seus súditos esse tipo de imaginação, fazendo com que o governante se torne uma figura tão obscura quanto temida (Burke, 1993, p. 66-7). A questão da escuridão e da obscuridade acaba então por revelar a ideia do diferente e do desconhecido, algo que assusta e provoca nos homens atitudes desmedidas, como o medo, a superstição, o fanatismo e a loucura. Como nos mostra Gérard Lebrun, se o pensamento do século XVIII se interessa tanto por tipos estranhos, como "iroqueses, persas, anões, gigantes, mágicos, diabos” (Lebrun, 1972, p. 128), é porque reconhece neles figuras do Outro da razão, alteridade que, ao mesmo tempo em que fascina, aterroriza. Esse embate com o Outro é, como dissemos, importante para própria racionalidade na medida em que a faz refletir acerca de seus limites e indica o espaço no qual a própria razão se desenvolve. Nas palavras de Lebrun: "A confrontação com o Outro tem, portanto, o efeito de me fazer duvidar do ponto de vista universal em que eu me instalaria" (Ibid., p. 128). Para uma razão que se julga esclarecida, é benéfico se defrontar com tudo o que pode lhe parecer novo ou estranho. Não se trata mais de temer ou evitar o desconhecido, mas, tal como em Rousseau, estabelecer um jogo ou diálogo com a escuridão, o suficiente para fazer dela um objeto comum, algo com o qual podemos nos comunicar. Assim é Saunderson, o cego

4 Trata-se de um dos textos contidos nos Ensaios sobre os Princípios da Moral e da Religião Natural (1751), no qual se lê: "O temor dos objetos desconhecidos incendeia a imaginação, a ponto de magnificar suas supostas qualidades malignas. É uma verdade bastante conhecida que a paixão tem grande influência na imaginação". (Kames, 2011, p. 39). 
da obra de Diderot analisada por Lebrun', assim também são os entusiastas, os habitantes de países exóticos, o bom selvagem, os loucos e todos os outros temas ou personagens que, de uma primeira estranheza ou diferença frente a um modelo comumente aceito de razão e normalidade, são elevados à condição de assuntos de filosofia. Um olhar mais atento descobrirá em casos como o do cego a oportunidade de entender melhor aquilo que vemos ou que pensamos ver: "Basta que adotemos o ponto de vista do cego para reduzir cultura, arte, moral, religião ao reflexo de uma aparência" (Ibid., p. 138 (grifo nosso)). Ao adotar a perspectiva de um outro, podemos compreender que a nossa é relativa, isto é: que existem outras maneiras de ver e que nossas crenças e opiniões podem ser ilusórias. No lugar de assustar, o que antes era tomado como signo de obscuridade e estranheza pode revelar muito acerca de nós mesmos. "É essa a ideia essencial da Aufklärung" (Ibid., p. 138), escreve Lebrun em uma passagem em que aproxima a Carta sobre os cegos da Crítica da razão pura e dos Sonhos de um visionário, duas obras de Kant. Perguntar-se pela relação entre ilusão e razão, entre sombras e luz, passa a ser uma das preocupações que marcam o Iluminismo. Não se pode mais ignorar ou rechaçar o Outro: "A época das Luzes se caracteriza pela descoberta dos outros em seu estrangeirismo" (Todorov, 2008, p. 142), diz Todorov em O espírito das Luzes. Trata-se, afirma Lebrun, de um novo modo de pensar para o qual tendem os autores deste século, uma maneira que desde então é chamada de antropologia:

Daí em diante a filosofia não irá mais se contentar em diluir a aparência na subjetividade e na desrazão. Estaremos sequiosos por explorar essa subjetividade e essa desrazão em si mesmas - a antropologia nascerá quando se tiver decidido estudar o homem através das figuras da não-verdade (Lebrun, 1972, p. 135). 
Indo ao encontro do que aqui é dito por Lebrun, Rubens Rodrigues Torres Filho reconhece em outro texto de Diderot aquele que talvez seja o melhor exemplo ou representante desse tipo de preocupação filosófica própria do século XVIII: O sobrinho de Rameau ${ }^{6}$. Nele, o embate entre a razão e o seu Outro se explicita, ganha corpo e voz nos dois interlocutores do diálogo que compõe a obra. De um lado, "o enciclopedista, defensor da sã razão e dos bons costumes", do outro "seu interlocutor desconcertante: o boêmio, o farsante, o bufão musical impertinente" (Torres Filho, 2004, p. 56). Por que um filósofo se interessaria em conversar com alguém como o sobrinho de Rameau, um homem que nem sequer tem uma identidade definida ${ }^{7}$ que atende pelo nome de seu tio, que não tem valores? Por que o filósofo "tem de se haver" com o que Rubens Rodrigues chama de seu "reverso, imagem invertida, talvez seu pesadelo" (Ibid., p. 57)? O que é o sobrinho de Rameau senão o fantasma do filósofo, sua sombra: a "exterioridade da irrazão, da loucura" (Torres Filho, 2004, p. 57)? Este homem que não é ninguém em especial, mas que é capaz de imitar a todos, que é mestre da pantomima e que revela a hipocrisia de uma sociedade cheia de ritos e ilusões, desconcerta o filósofo e sua filosofia. Por seu turno, esse filósofo, que é suficientemente flexível e livre para considerar seus pensamentos e ideias como sendo "rameiras", não deixa de se fascinar pela estranheza que o sobrinho de Rameau lhe provoca.

6 O próprio Rubens Rodrigues nos lembra da importância que esse texto teve para o Hegel da Fenomenologia do Espírito e para a análise que aí se apresenta do "jogo entre dois discursos, como iria dizer Hegel mais tarde: o da 'consciência honesta' e o da "consciência dilacerada" (Torres Filho, 2004, p. 56). Vale também lembrar do lugar que Michel Foucault atribui ao Sobrinho de Rameau: "O riso do Neveu de Rameau prefigura antecipadamente, e o reduz, todo o movimento da antropologia do século XIX" (Foucault, 2008, p. 348). Ou ainda: "Confrontação trágica entre a necessidade e a ilusão de um modo onírico, que anuncia Freud e Nietzsche, o delírio do Neveu de Rameau é ao mesmo tempo a repetição irônica do mundo, sua reconstituição destruidora no teatro da ilusão" (Foucault, 2008, p. 347).

7 É o que nota Michel Foucault nas páginas da História da Loucura dedicadas ao Sobrinho de Rameau. 
Começa então o que Rubens Rodrigues chama de um "jogo de espelho e de provocação" entre os dois, um tipo de disputa amigável que é também o encontro entre luzes e sombras ou, nas palavras de Rubens Rodrigues, "o encontro da Ilustração com os seu limites" (Ibid., p. 55). O objetivo deste texto é o de entender em que medida a Antropologia de Kant seria herdeira desta tradição que, como nos mostra Rubens Rodrigues, tem em Diderot um de seus maiores expoentes. Ou seja: em que sentido a Antropologia, sobretudo nos parágrafos que dedica ao tema da imaginação e da fantasia, poderia ser entendida como mais uma manifestação desse diálogo entre luzes e sombras, entre a razão e o seu Outro, diálogo tão característico do pensamento setecentista?

\section{O ponto de vista pragmático}

A Antropologia de um ponto de vista pragmático já traz em seu título o âmbito a partir do qual pretende tratar o seu objeto. Como afirma Kant em seu Prefácio, pragmático é o domínio que leva em consideração aquilo que o homem faz ou que deve fazer de si mesmo, por oposição ao fisiológico, no qual se estuda o que a natureza faz do homem. Trata-se, portanto, do ser humano sob o aspecto que o torna livre e autônomo: responsável por si mesmo ou por aquilo que ele pode e deve ser ${ }^{8}$. O próprio ponto de vista que o livro assume faz com que ele não possa se apresentar como sendo uma mera análise descritiva ou retrato passivo do universo humano, e sim como um meio de incitar em seu público o que nele há ou deve haver de humanidade (Menschlichkeit). Tem-se, assim, a pretensão de chamar a atenção do leitor para algo que o constitui como homem e, nesse sentido, o texto de Kant não busca despertar naquele ao qual se dirige nada senão o que ele já deveria saber: o fato de ser um homem, de poder ser ele mesmo.

8 "O conhecimento fisiológico do ser humano trata de investigar o que a natureza faz do homem; o pragmático, o que ele faz de si mesmo, ou pode e deve fazer como ser que age livremente" (Kant, 2006, p. 21). 
Há, nesse sentido, um problema que parece esvaziar e destituir de sentido todo o projeto em questão. Como alguém poderia querer ensinar algo que, em tese, todos já saberiam? O que significa ensinar alguém a ser ele mesmo e quem pode ser este que se coloca na posição de educador em tal caso? Existe aqui certa circularidade na medida em que a Antropologia é um livro acerca do homem, dirigida a homens e que, por isso mesmo, não poderia ser escrita senão por alguém que assume a postura ou lugar de um homem. A aparente obviedade revela a dificuldade do tema e nos mostra que, já em suas primeiras páginas, a Antropologia lida com uma concepção complexa de humanidade. O homem não é uma noção para a qual se busca uma definição, é antes uma tarefa, um tema que tem de ser cultivado, aprimorado, desenvolvido. Existe na ideia de homem apresentada na Antropologia uma ambiguidade que lembra aquela apresentada por Foucault - que, como se sabe, traduziu a Antropologia para o francês - quando discute o modo com que Kant trabalha a noção de menoridade em Que é o esclarecimento? (Was ist Aufklärung?), de 1783. De acordo com o filósofo francês, o alemão apresenta neste texto a menoridade como sendo "um fato, um processo que se desenvolve, mas ele (Kant) a apresenta também como uma tarefa e uma obrigação" (Foucault, 2001, p. 1383-4). A ideia de humanidade com que trabalham as primeiras páginas da Antropologia, aquelas que constituem o seu Prefácio, traz algo desse caráter ambíguo: a partir de certo aspecto, o homem é algo dado, um "fato" do qual se parte. Sob outro ponto de vista, a humanidade é um elemento que deve ser sempre desenvolvido tal como uma tarefa ou dever sem o qual os próprios homens deixariam de ser o que são. É nesse sentido que a humanidade é menos um ponto ao qual se chega ou que se conquista por completo do que algo a ser exercido, mantido e cuidado.

O mesmo Foucault, na introdução que escreveu para a sua versão da Antropologia, sugere que se nas Críticas Kant preocupara-se em delimitar e legitimar os âmbitos e os usos adequados 
às faculdades do sujeito universal (Foucault, 2008)', agora ele se pergunta pela atuação dessas mesmas faculdades no homem, considerado em sua singular condição de indivíduo, distinto dos demais, e que, no entanto, pode e deve buscar ser um "cidadão do mundo" (Kant, 2006, p. 95). A noção de homem não pode aqui ignorar todas as particularidades que constituem a vida humana: ser do sexo masculino ou do feminino, ser alemão ou francês, dessa ou daquela raça etc. ${ }^{\circ}$ Esse mundo do qual fala a Antropologia está repleto de características distintivas ou personalidades distintas e, no entanto, é a partir delas que os homens podem desenvolver o que neles é humano" ${ }^{11}$ O homem precisa praticar um tipo de olhar que, a partir das diferenças que percebe ao seu redor, o faça compreender o que o une aos demais. Tal como a de homem, a

9 No corpo da Antropologia há passagens que corroboram essa leitura, tal como a que se apresenta no final do parágrafo 40, em que Kant discute as diferentes maneiras com que a faculdade conhecer superior (que consiste de entendimento, juízo e razão) se manifesta de modo diverso em cada um dos homens: "Deixai-nos fazer agora observações sobre o ser humano (Mensh), como um se diferencia do outro nesses dons da mente ou no uso habitual deles, primeiramente numa alma saudável, mas logo também no caso de doença mental" (Kant, 2008, p. 95).

10 É o que Kant já afirmara na Introdução ao curso de antropologia do semestre de inverno de 1781/82: "Faz parte, portanto, do conhecimento do homem um ensinamento completo do que é diverso e característico no homem. Esses dois últimos fatores são de grande importância e têm sempre de vir antes no conhecimento dos homens, e é por meio deles que se tem de ampliar as experiências" (Ibid., p. 255-256).

11 Acerca da novidade que tal "ponto de vista pragmático" representou quando levado à universidade e tornado objeto de reflexão e de trabalho para o professor Kant, que dele fez o tema de um curso que ministrou e aperfeiçoou por décadas na Universidade de Königsberg (ver a esse respeito as introduções que Clélia Aparecida Martins e Michel Foucault fazem para as suas respectivas traduções da Antropologia de um ponto de vista pragmático), vale lembrar o que nos diz Márcio Suzuki na Apresentação que redigiu para a tradução que fez para a Introdução escrita por Kant por ocasião do curso de Antropologia do semestre de inverno de 1781/82. Nela, diz-nos Suzuki: "Os cursos de antropologia têm chamado a atenção dos estudiosos por ser um germinadouro de temas e noções que serão desenvolvidos em diferentes domínios do sistema. Não menos importante que esse aspecto é perceber o quanto Kant enfatiza a importância e novidade da própria disciplina, por ele introduzida pela primeira vez na grade dos estudos filosóficos. Kant tem plena consciência de que é o primeiro a conseguir levar a nova acepção de mundo para dentro da universidade, quando afirma que a antropóloga pragmática não é ensinada em nenhuma outra academia da Europa. A esse respeito, também se pode ler nos cadernos dos alunos do curso de 1784-1785: 'Até hoje ninguém apresentou a antropologia dessa maneira, isto é, como conhecimento do mundo, e Herr Professor Kant foi o primeiro a fazer um plano para ela e a expô-la em suas aulas"” (Ibid., 252-3). 
de antropologia também aparece como uma noção que deve ser ampliada e cultivada:

Viajar, ainda que seja apenas pela leitura de relatos de viagem, é um dos meios de ampliar o âmbito da antropologia. Mas para ampliá-la numa dimensão maior é preciso ter primeiro adquirido conhecimento do ser humano (Mensch $=$ homem) em sua própria terra, por meios das relações com os conterrâneos da cidade ou do campo, se se quer saber o que se deve buscar fora. Sem um tal plano (que já pressupõe o conhecimento do ser humano $($ Mensch = homem)), a antropologia do cidadão do mundo fica sempre muito limitada (Ibid., p. 22).

Mais uma vez estamos diante da circularidade que envolve o tema aqui exposto: viajar para conhecer os homens e a natureza humana só faz sentido quando já se sabe o que é ser um homem. A tarefa é dupla: ver o que está dentro ou próximo não é distinto da observação do que é estrangeiro ou longínquo. Por isso, é preciso viajar, se por isso entendermos a observação do que é diferente, pois é esse o meio de compreender o que há de comum entre mim e os demais. E é desse ponto de vista que o homem não pode ver os outros sem que veja a si próprio ao mesmo tempo. O final do Prefácio que Kant escreve para a Antropologia não deixa de lembrar-nos de que existem "consideráveis dificuldades intrínsecas à própria natureza humana" (Ibid., p. 22) que impedem esse tipo de exercício. Não há como observar o homem (seja ele um outro ou nós mesmos) sem que tenhamos de nos haver com todos os problemas e singularidades próprios da condição humana. Nem tudo é claro quando se busca entender o homem e não se pode ter qualquer êxito em tal empreendimento até que se reconheça que muito do que aí se mostra como sendo obscuro provém da própria natureza humana e é parte integrante dela. É preciso então compreender que a fonte da escuridão não nos é exatamente estranha, como poderia parecer em um primeiro momento, e que, por esse motivo, nós mesmos somos os culpados por não nos conhecermos melhor. 


\section{Menoridade}

No parágrafo 59 da Antropologia, parágrafo que encerra o Livro I desta obra, Kant escreve o seguinte:

A mais importante revolução no interior do ser humano é 'a saída deste do estado de menoridade em que se encontra por sua própria culpa'. Enquanto até aqui outros pensaram por ele, e ele simplesmente imitou ou precisou de andadeiras, agora, vacilante ainda, ele ousa avançar com os próprios pés no chão da experiência (Ibid., p. 126 (grifo nosso)).

Essa passagem que ecoa as primeiras linhas do conhecido Was ist Aufklärung? traz uma nuança que a distingue do que havia sido dito no referido texto. Se no artigo de 1783 Kant destacara os aspectos exteriores e públicos da menoridade, se ali se chamava a atenção para a "menoridade religiosa", considerada como sendo "a mais prejudicial e mais danosa" (Kant, 1985, p. 114) quando comparada às artes e às ciências, na Antropologia a menoridade diz respeito a um âmbito interior, isto é: à incapacidade que o indivíduo tem de regrar suas próprias faculdades ou à dificuldade que encontra para exercer sua natureza humana. Embora possamos pensar que se trata da mesma questão, agora ela não é mais considerada tal como em Was ist Aufklärung? Para a Antropologia, ao menos em um primeiro momento, importa perguntar-se por aquilo que, no interior mesmo do homem, o impede de atingir a maturidade e não o deixa pensar por si próprio. A ideia de um mundo esclarecido e cosmopolita não pode aqui desconsiderar esse âmbito interno. O "outro" que em Was ist Auklärung? é antes de tudo um "outro indivíduo" (Ibid., p. 100) que assume a direção do nosso entendimento (que pode ser o autor de um livro, um médico ou um pregador, como nos diz Kant), agora se mostra como tendo uma feição muito mais íntima e próxima: ele já não é exatamente externo e pode mesmo estar dentro de nós. Mais do que nunca, é preciso ressaltar a nossa culpa diante da passividade que nos torna imaturos e nos mantém nas trevas: 
A que infantilidades não desce o homem, mesmo em idade adulta, quando se deixa levar pela trela da sensibilidade! Vamos ver agora quanto ele faz de melhor, ou pior, quando segue o seu caminho à luz do entendimento (Id., 2006, p. 94).

Entendimento e sensibilidade: esses são os termos a partir dos quais o embate entre luzes e sombras é apresentado no Livro I da Antropologia. De um lado, o entendimento como a faculdade superior de conhecimento: o polo ativo, iluminado e nobre da mente. De outro, a sensibilidade: passiva, obscura, inferior. Kant chega mesmo a comparar a sensibilidade a um povo ou plebe que diante da nobreza do entendimento solicita o seu governo e sua legislação. Por esse motivo, explica-nos o filósofo de Königsberg, é equivocada a opinião segundo a qual a sensibilidade é a fonte de nossos erros e equívocos, que é a origem da confusão e da obscuridade em nossas representações, pois em sua passividade ela não poderia ser causa de nada:

O que há de passivo na sensibilidade, que no entanto não podemos pôr de lado, é propriamente a causa de todo o mal que a ela se atribui. A perfeição interna do ser humano (Mensch= homem) consiste nisto: ter o uso de todas as faculdades em seu poder, para submetê-lo ao seu livre-arbítrio. Mas para isso se exige que o entendimento domine sem, contudo, debilitar a sensibilidade (que é em si plebe, porque não pensa), porque sem ela não haveria matéria que pudesse ser elaborada para uso do entendimento legislador (Ibid., p. 43 (grifo nosso)).

O uso, diríamos, saudável das faculdades de conhecimento depende então de uma boa relação ou diálogo entre entendimento e sensibilidade - é preciso que o entendimento saiba lidar com esta que é a fonte de toda matéria sobre a qual ele julga e pensa. Mas, salienta Kant, não é sempre isso o que ocorre: “com bastante frequência somos também o jogo de representações obscuras que 
não querem desaparecer, mesmo que o entendimento as ilumine" (Ibid., p. 36). Quando se observa o modo como as faculdades operam nos homens, observação própria de uma antropologia pragmática, percebe-se que muitas vezes o entendimento julga mal e no lugar de controlar a sensibilidade parece ser dominado por ela. Por mais que saiba que não poderá desfrutar da bela paisagem do local em que deseja ser enterrado, exemplifica Kant, um moribundo não deixa de se preocupar com a questão e faz o possível para assegurar-se de que passará toda a eternidade no lugar sonhado. Como explicar esse tipo de ideia ou ficção que extrapola qualquer entendimento racional e se impõe à mente com tamanha força que já não consideramos a obscuridade nele encerrado? Compreender como isso é possível e buscar uma maneira de sanar os problemas que tal procedimento pode causar à mente demanda uma reflexão acerca da natureza da sensibilidade e do que nela, malgrado sua passividade, poderia assumir certo caráter ativo. Enfrentar esse paradoxo, e se perguntar pelo sentido a partir do qual aquilo que deveria ser passivo acaba por agir, é a maneira com que o próprio entendimento pensa (uma vez que apenas ele é quem pensa) seus limites e sua complexa relação com o outro lado da faculdade de conhecer. Para bem dominá-la, sem correr o risco de debilitá-la, é necessário que o entendimento tente entender a sensibilidade. De acordo com Kant, a faculdade inferior de conhecimento é dividida em duas. A primeira delas é o domínio dos sentidos que, por seu turno, se dividem em dois:

Os sentidos, porém, são divididos por sua vez em sentido externo e sentido interno (sensus internus); o primeiro é aquele em que o corpo humano é afetado por coisas corporais (körperliche Dinge ${ }^{12}$ ), o segundo, aquele em que é afetado pela mente [...] (Kant, 2006, p. 52).

12 "Coisas físicas", na tradução de Foucault. 
O parágrafo 24 ainda nos adverte do pertencimento desse sentido interno ao lado passivo da faculdade de conhecer: "O sentido interno não é a pura apercepção, uma consciência do que o ser humano $\mathrm{faz}$, pois esta pertence à faculdade de pensar, mas o que ele sofre quando é afetado pelo jogo de seus próprios pensamentos" (Ibid., p. 6o). Não se trata então de uma consciência, no sentido em que essa pressuporia alguma ação, mas antes de algo como uma receptividade (passiva) frente à atividade dos próprios pensamentos e, por isso, parte da sensibilidade e não do entendimento. Por sua vez os sentidos externos são os cinco que comumente estão presentes nos homens: tato, audição, visão, paladar e olfato. Ao lado dos sentidos (interno e externo) Kant apresenta a imaginação como a outra grande parte que constitui a sensibilidade, a respeito da qual diz o seguinte no parágrafo 28 da Antropologia:

A imaginação (facultas imaginandi), como faculdade de intuições mesmo sem a presença do objeto, é ou produtiva, isto é, uma faculdade de exposição original do objeto (exhibitio originaria), que, por conseguinte, antecede a experiência, ou reprodutiva, uma faculdade de exposição derivada (exhibitio derivativa) que traz de volta ao espírito uma intuição empírica que já se possuía anteriormente. - As intuições puras do espaço e do tempo pertencem à primeira exposição, todas as restantes supõem uma intuição empírica, que, quando se une ao conceito do objeto e se torna, pois, conhecimento empírico, se chama experiência (Ibid., p. 66).

De modo rápido e sucinto, Kant reitera aqui um tema já exposto na Crítica da razão pura: um uso da imaginação ligado à exibição das intuições a priori de tempo e espaço e um uso ligado à experiência e que se distingue pela apresentação de intuições empíricas. O filósofo ainda chama a atenção para uma faceta, se assim podemos dizer, da imaginação que, embora possa trabalhar com elementos oriundos da experiência, não o faz de modo a simplesmente exibi-los como a mera imaginação reprodutiva, mas trabalha a partir da "matéria" que os sentidos lhes oferecem 
para a elaboração de suas “criações (Einbildungen)" (Ibid., p. 67), uma imaginação que Kant chamará de artística ou poética. Em meio a essas passagens surge o tema da fantasia:

A imaginação, quando produz involuntariamente ficções (Einbildungen), se chama fantasia. Aquele que está habituado a tomar essas ficções por experiências (internas ou externas) é um fantasista (Ibid., p. 66).

Um pouco mais à frente, no parágrafo 31, a questão reaparece nos seguintes termos:

Antes de o artista poder construir uma figura corpórea (como que palpável) ele precisa tê-la construído em sua imaginação, e essa figura (Gestalt) é então uma ficção (Dichtung) que, quando involuntária (como no sono), se chama fantasia e não pertence ao artista; mas quando regida pelo arbítrio é denominada composição, invenção. (...) Jogamos frequente e prazerosamente com a imaginação, mas a imaginação (como fantasia) também joga tão frequente e às vezes muito inoportunamente conosco (Ibid., p. 73).

Diferentemente do que ocorre com a composição ou invenção, que são produtivos e voluntários, na fantasia é a imaginação que joga conosco e não o contrário. No sono, diz-nos Kant, esse jogo é saudável na medida em que proporciona às faculdades um necessário relaxamento "para recobrar as forças utilizadas quando se está acordado” (Ibid., p. 74). O sonho que então se produz garante um descanso e uma diminuição das atividades sem que as faculdades parem por completo, o que seria a morte. Trata-se, portanto, de um uso involuntário e benéfico da imaginação produtiva. O mesmo não ocorre quando a fantasia atua na vigília; nesse caso, afirma Kant, estamos diante de um "estado doentio" (Ibid., p. 74), similar ao de alguém que sonha acordado e, por isso, toma ficção por realidade. Todos os distúrbios, desregramentos e tormentos aos quais está sujeita a mente humana apresenta algu- 
ma relação com esse tipo de imaginação produtiva e involuntária: “a (fantasia) desregrada se aproxima da loucura, onde a fantasia joga com o ser humano, e o infeliz não tem de modo algum em seu poder o curso de suas representações" (Ibid., p. 80). Encontramos aqui a fonte de toda obscuridade que atrapalha e perturba o entendimento, a origem das "figuras monstruosas" que surgem como "imagens de sonho de alguém acordado" (Ibid., p. 73). De acordo com o modo como a relação entre entendimento e sensibilidade se apresenta em cada um dos homens, esses distúrbios ou tormentos podem ganhar distintas peculiaridades ou traços: a hipocondria, a melancolia, a amência, a demência, a insânia, a vesânia'³ e até o egoísmo e a megalomania que o acompanha podem ser contatos entre os distúrbios que impedem o indivíduo de realizar sua natureza humana de modo pleno e que, por isso, os mantém em um estado de menoridade. No fundo, o que se percebe nesses casos é uma incapacidade, da qual o homem é o verdadeiro culpado, em lidar com sua própria sensibilidade: com o seu Outro interno, para empregar o termo usado por Lebrun quando discutia a tendência antropológica inaugurada pelo pensamento do século XVIII. Se a imaginação, como fantasia, joga conosco, isso é culpa de nosso entendimento que ainda não ousou agir de acordo com a função que o caracteriza e iluminar a matéria obscura que ela lhe apresenta, no lugar de simplesmente temê-la ou perturbar-se com ela. Como parecem sugerir as linhas que compõem a Antropologia, cada um de nós nasce com uma disposição natural e peculiar que nos faz tender para algum tipo específico de distúrbio mental: podemos ter certa inclinação para a melancolia ou para a hipocondria ou então para aquilo que Kant chama de insânia etc. No entanto, justamente porque aqui as doenças ou fraquezas são mentais e não exatamente corpóreas ou físicas, porque dizem mais respeito ao âmbito pragmático

13 Ver, por exemplo, o parágrafo 45 da Antropologia de um ponto de vista pragmático. 
(aquele se preocupa com o que o homem faz de si mesmo ou deveria fazer) e não ao fisiológico (que trata de investigar o que a natureza faz do homem), sua possível cura não poderia depender de outro, senão do próprio doente. Por isso mesmo, parece ser tão difícil determinar com precisão o que vem a ser o homem normal ou são, uma vez que a saúde mental refere-se a diferentes equilíbrios, medidas e proporções que dizem respeito à disposição na qual se apresentam as faculdades de um certo homem: o modo como um hipocondríaco regula sua fantasia não é igual àquele com que o melancólico ordena sua imaginação. A atenção aos casos e às particularidades que os distinguem são elementos que uma antropologia pragmática não pode ignorar. Por esse mesmo motivo, pensamos, a loucura, como nome maior que encerra os casos de distúrbios, também não pode ser objeto de uma definição precisa. No limite, dela Kant apenas poderá dizer:

O único sinal universal da loucura é a perda do senso comum (sensu communis) e a substituição dele pelo senso lógico privado (sensus privatus), por exemplo, quando em dia claro um indivíduo vê sobre sua mesa uma luz bem forte que um outro ali presente não vê, ou quando ouve uma voz que nenhum outro ouve. Pois é uma pedra de toque subjetivamente necessária da retidão de nossos espíritos em geral e, portanto, também da saúde de nosso entendimento, que o confrontemos com o entendimento de outros, e não nos isolemos com o nosso e julguemos como que publicamente com nossa representação privada (Ibid., p. 116 (grifo nosso).

De modo geral, loucos e "doentes do entendimento" são aqueles incapazes de conviver em sociedade. Por esse motivo, a vida social surge como sendo o melhor antídoto contra todo o tipo de distúrbios mentais. Toda "dietética da mente" Ibid., p. 105) 14 acaba por se referir a uma participação na sociedade. Já nos Cur- 
sos de Antropologia, que Kant ministrou durante anos e que são a fonte do livro que leva o mesmo nome, o filósofo de Königsberg chamava a atenção para a importância que o "mundo" tem para o conhecimento do homem: "O homem conhece o mundo, isto é, ele conhece o homem em todas as condições" (Id., 2008 (grifo nosso)). Em nota à tradução dessa passagem, Márcio Suzuki nos adverte que o termo que aqui verte por condições é Ständen, plural de Stand, que também poderia ser traduzido por situações, posições, lugares ou mesmo por status, a condição social que se ocupa em determinada comunidade ${ }^{15}$. $\mathrm{O}$ mundo pressupõe então o conhecimento dos variados lugares, situações, posições ou postos nas quais a natureza humana pode se manifestar. Uma vez que é sempre mais difícil observar a mim mesmo e reconhecer em mim todos esses movimentos ou situações nas quais se manifesta a natureza humana, diz-nos Kant nesses Cursos de antropologia, a observação dos outros aparece como sendo o melhor modo de entender o que vem a ser o homem: o conhecimento do homem que sou ou devo ser depende da constatação do que nos outros, distintos de mim, há de humano. Encontramos aqui uma ponte que liga o âmbito mais íntimo e interno da natureza humana à exterioridade do mundo social. Mas que sociedade é essa que a Antropologia nos propõe? Afinal, quais seriam as especificidades desse mundo que um ponto de vista pragmático nos permite vislumbrar?

\section{O caminho da maturidade}

No início do parágrafo 14 da Antropologia, Kant escreve o seguinte:

Feitas as contas, quanto mais os seres humanos (die Menschen) se tornam civilizados, tanto maior é o número de atores (Schauspiler); eles

15 Trata-se da nota 4 da tradução citada dos Excertos dos cursos de antropologia de Immanuel Kant. 
aparentam simpatia, respeito pelos outros, recato, altruísmo, sem enganar ninguém com isso, porque cada um dos demais está de acordo que não se está sendo exatamente sincero, e também é muito bom que as coias sejam assim no mundo. Pois, porque os homens representam esse papel (Denn dadurch, dass Menschen diese Rolle spielen), as virtudes, cuja aparência apenas afetam por um longo espaço de tempo, são por fim pouco a pouco realmente despertadas e passam a fazer parte do caráter. - Enganar, porém, o enganador que há em nós mesmos, enganar a inclinação é, por sua vez, voltar a obedecer à lei da virtude, não engano, mas inocente ilusão de nós mesmos (Id., 2006, p. 5 (grifo nosso)).

O mundo humano é um local ou lugar que depende de uma certa arte, similar à do ator, em que é preciso que enganemos não apenas os outros, mas sobretudo a nós mesmos. A vida em sociedade demanda certa "hipocrisia" que não é má e que não visa nada outro senão o estabelecimento das próprias condições sem as quais o que há de humano em nós não poderia se desenvolver, isto é: visa estabelecer o que Kant aqui chama de mundo. Se fôssemos incapazes desse tipo de atuação ou desempenho (Spiel) não poderíamos responder às nossas inclinações naturais que, segundo Kant, nos levariam à comodidade, definida como sendo "repouso não procedido de esforço" (Ibid., p. 51). Para sermos homens, cada um de nós em sua singularidade, temos de ser capazes de dissimular as inclinações que nos levariam a um estado em que se "vegeta sem finalidade" (Ibid., p. 51). Seríamos escravos de nós mesmos, de nossa própria natureza, caso não fôssemos capazes de ir além dela e, por arte, encontrar os meios de enganar aquilo que, em nós mesmos, nos impede de sair de um estado de menoridade - a sensibilidade:

Com violência nada se conseguiu contra a sensibilidade nas inclinações; é preciso ludibriá-las e, como Swift, dar um tonel para a baleia brincar (dem Walfish eine Tonne zum Spiel hingeben), a fim de salvar o navio (Ibid., p. 51). 
É preciso que se saiba brincar ou jogar (spielen) com a sensibilidade. Trata-se, portanto, de uma arte a partir da qual o homem, distanciando-se de si mesmo ou de sua natureza, torna-se capaz de não apenas controlar o que nele é obscuro e incerto, mas também de encontrar o papel ou personagem que lhe cabe no mundo. É também a forma pela qual ele pode lidar ou se comunicar com a diferença ou com um Outro, seja ele interno ou externo. A referência à arte teatral torna-se mais clara nos Cursos de antropologia, nos quais Kant chama a atenção para o fato de que o homem no mundo teria de agir ou atuar tal como um bom ator que sabe que para desempenhar bem o seu papel não pode confundir os seus sentimentos aos do personagem que representa (Id., 2008). Essa mesma distância necessária ao ator é também imprescindível ao homem: sair da menoridade é, nesse sentido, conseguir ir além das inclinações, ludibriá-las e compor um caráter que não pode ser fruto exclusivo da mera natureza e, por isso, requer certa arte. Não há aqui como não lembrar do que diz Diderot a propósito do ator em o Paradoxo sobre o comediante. De acordo com o enciclopedista, os bons comediantes são aqueles que são insensiveis, ou seja: aqueles que conseguem manter uma distância frente aos sentimentos dos personagens que representam e, assim, tornam-se senhores de seu desempenho. O mesmo Diderot, nessa mesma obra, não deixa de destacar o quanto tal distância seria benéfica à sociedade: homens menos calorosos e mais frios, menos passivos diante de sua sensibilidade, estariam em condições de julgar melhor acerca de todas as situações e, por isso, serem mais virtuosos. Para Kant, assim como para Diderot, a vida social reivindica certas aparências e dissimulações que não entram em conflito com a ideia maior de moral ou virtude: "A cortesia (polidez) é uma aparência de condescendência que infunde o amor" (Id., 2006, p. 51), escreve o filósofo de Königsberg. A pudicícia e o decoro, ele acrescenta, são da mesma ordem e exigem o mesmo nível de ilusão ou engano, sem deixar de ser vir- 
tuosos. Há muito de teatro na vida social ou no que a Antropologia chama de mundo: para o bem da sociedade e do homem que nela deve viver é preciso saber jogar ou atuar (spielen). Nada seria mais prejudicial ao mundo do que homens que dissessem ou agissem de acordo com que naturalmente sentem. Apenas os loucos ou perturbados parecem ignorar ou ter problemas em aceitar esse tipo de jogo, desempenho ou performance (Spiel, jeu), que, no fundo, não é senão uma inabilidade em saber lidar com os outros ou com o Outro. O que é, por exemplo, o sobrinho de Rameau senão alguém que se revolta diante da constatação de que o mundo é feito de jogos, hipocrisias, pantomimas ou do que ele chama de "idiotismos"? Sua loucura, que se confunde com certa ingenuidade, reside justamente no fato de revelar que a sociedade é um palco. Por isso mesmo ele se torna tão interessante para o filósofo com quem conversa: "Havia em suas palavras muita coisa que pensamos, que dirige nossa conduta, mas que calamos" (Diderot, 2000, p. 374). O sobrinho de Rameau vê hipocrisia por todos os lados e, por essa razão (se é que aqui podemos falar exatamente em razão), torna-se ele mesmo a denúncia do que percebe: no lugar de atuar ou agir, ele reage. Não quer fazer parte do jogo e em vez de assumir um papel determinado na cena social, prefere ser o louco, o abjeto, o marginal que se esconde na indistinção das sombras.

E, no entanto, por mais louco, arredio e estranho que ele seja, por mais sombrio que se apresente, ele ainda se apresenta. Ele conversa com o filósofo e embora afirme as mais confusas e obscuras das ideias, ainda fala e estabelece com o seu opositor, o filósofo, uma interlocução. Por mais indistinto que possa parecer à primeira vista, o sobrinho de Rameau ainda é um personagem que desempenha o seu papel, que se coloca em uma situação, e malgrado toda a confusão de suas palavras e postura ainda se mostra como sendo um personagem ou caráter na medida em que se põe a falar com esse filósofo, homem esclarecido e suficientemente sábio para ouvi-lo. Como quem lança o tonel para 
entreter a baleia, o filósofo - que é também o narrador que dirige a cena do diálogo - acaba por ludibriar o seu oponente quando o transforma em interlocutor. O que era signo de loucura e diferença se aproxima no momento em que a ele é dada a oportunidade de falar: o que era escuridão se ilumina e o outro, embora mantenha sua estranheza e alteridade, mostra-se alguém com o qual é possível estabelecer algum nível de comunicação. Ao dialogar, o sobrinho já nos indica que não é tão louco ou obscuro como poderia parecer em um primeiro momento. Ao falar com ele, ao ouvi-lo e, em certa medida, compreendê-lo, o filósofo já não é puramente luz e claridade. Luzes e sombras, como nos dizia Rubens Rodrigues, entram aqui em contato. Não parece ser de outro nível o tipo de relação que a Antropologia defende como sendo a mais adequada entre entendimento e sensibilidade quando diz que cabe ao primeiro o cuidado de não debilitar ou violentar a segunda. É necessário que o homem, justamente quando precisa ser humano, desenvolva sua capacidade de lidar ou jogar consigo e com os outros.

Por fim, resta-nos perguntar como um texto como a Antropologia poderia pretender estimular em seu leitor esse tipo de procedimento ou arte que nos faz controlar o que em nós é obscuro, tal como um ator que domina o personagem que representa? Em outros termos: como um livro deveria se apresentar quando não busca, como dizia Kant em Was ist Aufklärung?, fazer as vezes do entendimento de seu público, mas antes procura esclarecê-lo e fazê-lo pensar por si mesmo? Uma passagem da própria Antropologia pode nos ser de grande ajuda a esse respeito. Nela diz Kant:

Mas em geral um certo teor enigmático numa obra não é desagradável ao leitor, porque com isso se lhe tornará sensível a própria sagacidade para resolver o que é obscuro em conceitos claros (Kant, 2006, p. 37).

Quando deseja esclarecer o seu leitor e nele estimular a capacidade de pensar por si, um autor não pode tomar a posição de 
seu tutor. Por isso, sua obra deve se apresentar como um misto de luzes e sombras, dando ao seu público o espaço e a oportunidade de estabelecer um tipo de diálogo que não é distinto daquele que deve imperar no mundo e na relação dos homens com eles próprios. Como não deixa de indicar a metáfora visual, um texto que fosse inteiramente luz - que se pretendesse portador de uma verdade incontestável - ofuscaria o seu leitor e, nesse sentido, não seria distinto da mais profunda escuridão:

Quanto mais intensamente os sentidos se sentem afetados, ainda que o grau de influxo exercido sobre eles permaneça o mesmo, tanto menos eles ensinam. Ou inversamente: para que ensinem muito, precisam ser moderadamente afetados. Quando a luz é mais intensa, nada se vê (distingue), e uma voz de estentor ensurdece (abafa o pensamento) (Ibid., p. 57).

Uma vez que a Antropologia pretende menos definir com precisão o que vem a ser o homem do que estimular e promover em seu público o que nele é humano, é preciso que o próprio texto se apresente como sendo uma obra que requer o trabalho e a atividade do público ao qual se dirige. A Antropologia exige um leitor ativo, que, no limite, possa fazer desse livro um meio de chegar a ele mesmo, como nos mostra Kant já no seu Prefácio: sua obra tem de ser "popular", plena de "exemplos que o leitor possa por si mesmo encontrar" (Ibid., p. 23). A partir de variados exemplos dados pelo filósofo de Königsberg, como o do tonel e da baleia acima referido, cada um de nós pode pensar em um caso específico que nos diz respeito, isto é: podemos encontrar o nosso próprio exemplo. Ao público é dada a ocasião de um diálogo no qual a própria obra encontra o seu tema: como dissemos, aqui o homem é menos um objeto sobre o qual se discorre do que algo ao qual se dirige e se busca formar. Para se realizar e esclarecer seu público, a própria Antropologia, como obra, não poderia ignorar o lugar e a voz daquele que é o seu lado obscuro: o seu próprio leitor. Como o filósofo que dialoga com o sobrinho de Rameau, 
o texto de Kant não pode nem prescindir, tampouco ter medo, de uma interlocução com este que é o seu Outro - é preciso que a Antropologia pressuponha um diálogo com seu público, que não queira simplesmente doutriná-lo, debilitá-lo ou violentá-lo, para empregar os termos usados por Kant quando tratava da relação entre entendimento e sensibilidade.

Desse ponto de vista, para que o próprio processo de esclarecimento ou saída da menoridade se dê, seria preciso pensar que as Luzes, como se diz em português ou em francês - les Lumières - são sempre plurais, que não poderia haver uma única e absoluta luz singular que se sobreporia a todas as demais. Toda difusão, comunicação ou transmissão de conhecimento dependeria de uma noção de verdade que precisa ser irisada ${ }^{16}$, que se mostra como uma diversidade multicolorida de tons e intensidades, de claros e escuros, sem os quais os diálogos, os diferentes pontos de vista e posições estariam fadados ao fracasso. Nesse sentido, todo o medo do escuro se dissipa quando se percebe que do outro lado da luz que vemos não há uma escuridão total, mas apenas outra intensidade, cor ou tonalidade de luz com a qual poderemos entrar em contato. Ou ainda, para terminarmos com a frase de Diderot que serviu de epígrafe para esse texto: é preciso lembrar que há cores na sombra ${ }^{17}$.

16 A expressão é empregada por Bento Prado Jr. ao examinar a noção de verdade em Rousseau: "De outro lado, como um raio de luz que atravessa o prisma, a verdade, única, é irisada nas suas diferentes faces sociais e se dispersa: para cada lugar, sua cor; Paris, Genebra..." (Prado Jr., 2008, p. 373).

17 A passagem nos parece tão ilustrativa acerca das luzes ou "das Luzes" que talvez merecesse ser citada na íntegra. Na tradução de J. Guinsburg, com a qual trabalhamos ao longo de todo nosso texto: "Meu amigo, as sombras também têm suas cores. Observai atentamente os limites e mesmo a massa da sombra de um corpo branco; e discernireis aí uma infinidade de pontos negros e brancos interpostos. A sombra de um corpo vermelho tinge-se de vermelho (...). A sombra de um corpo com a carne e o sangue da pele forma um débil tom amarelado. A sombra de um corpo azul toma uma nuança de azul; e as sombras e os corpos refletem-se uns sobre os outros. São estes reflexos infinitos das sombras e dos corpos que engendram a harmonia sobre a vossa secretária, onde o trabalho e o gênio jogaram a brochura do livro, o livro ao lado da corneta [comet, no original - "rolo de papel" na tradução de Enid Abreu Dobránszky], a corneta em meio a cinquenta objetos díspares de natureza, de forma e de cor" (Diderot, 1993, p. 177). 


\section{Bibliografia}

BURKE, E. Uma investigação filosófica sobre a origem de nossas ideias do sublime e do belo. Tradução de Enid Abreu Dobránszky. Campinas, Editora da Unicamp/Papirus, 1993.

DIDEROT, D. Ensaios sobre a pintura. In: Diderot-Obras II, Estética, Poética e Contos. Tradução J. Guinsburg. São Paulo, Perspectiva, 2000. . Ensaios sobre a pintura. Tradução de Enid Abreu Dobránszky. Campinas, Editora da Unicamp/Papirus, 1993.

. Essai sur la peinture. In: Oeuvres. Bibliothèque de la Pléiade. Paris, Gallimard, 1951.

Paradoxo sobre o comediante. In: Diderot - Obras II, Estética, Poética e Contos. Tradução de J. Guinsburg. São Paulo, Perspectiva, 2000.

O sobrinho de Rameau. Tradução de Marilena de Souza Chauí Berlinck. São Paulo, Col. Pensadores, Abril, 1973.

Le neveu de Rameau. In: Oeuvres. Bibliothèque de la Pléiade. Paris, Gallimard, 1951.

FOUCAULT, M. Introduction à l'Anthropologie. In: KANT, I. Anthropologie du point de vue pragmatique. Tradução de Michel Foucault. Paris, Vrin, 2008.

. Qu'est-ce que les Lumières?. In: Dits et écrits II. 1976-1988. Paris, Gallimard, 2001.

. História da loucura na Idade Clássica. Tradução de José Teixeira Coelho Neto. São Paulo, Perspectiva, 2000.

KANT, I. Antropologia de um ponto de vista pragmático. Tradução de Clélia Aparecida Martins. São Paulo, Iluminuras, 2006.

Resposta à pergunta: Que é 'Esclarecimento?'. In: Immanuel Kant - Textos seletos, ed. bilíngue. Tradução de Floriano de Souza Fernandes. Petrópolis, Vozes, 1985.

Excertos dos cursos de antropologia de Immanuel Kant. Tradução de Márcio Suzuki. Disponível em: <www.anpof.org.br/spip. php?article1o7\#nb1>. Acesso em setembro de 2011.

Anthropologie du point de vue pragmatique. Tradução de Michel Foucault. Paris, Vrin, 2008.

Anthopologie in pragmatischer Hinsicht. In: Kants Werke. Berlin, Walter de Gruyter \& Co., 1968, vol. VII.

. Introdução à Antropologia - semestre de inverno 1781/82. Tradução Márcio Suzuki. In: Discurso 38 (2008), p.253-261. 
KAMES (Henry Home) Temor dos poderes sobrenaturais na escuridão. Tradução Daniel Lago Monteiro. Rapsódia, número 5. (2011), p. 3541.

LEBRUN, G. O cego e o filósofo ou nascimento da antropologia. In: Discurso 3 (1972), p. 127-140.

LOCKE, J. An essay concerning human understanding. Chicago, W. Benton/University of Chicago, 1952.

Quelques pensées sur l'éducation. Tradução de G. Compayré, introdução e notas de J. Chateau. Paris, Vrin, 1992.

PRADO JR., B. Não dizer a verdade equivale a mentir?. In: A retórica de Rousseau. São Paulo, Cosacnaify, 2008.

ROUSSEAU, J-J., Emílio ou da educação. Tradução de Roberto Leal Ferreira. São Paulo, Martins Fontes, 1999.

SANTOS, L.R.R. O aprimoramento moral na antropologia pragmática de Kant. São Paulo: Dissertação de mestrado apresentada ao Departamento de Filosofia da Universidade de São Paulo, 2011.

SUZUKI, M. Apresentação à Introdução à Antropologia - semestre de inverno 1781/82. In: Discurso 38 (2008), p. 249-253.

TERRA, R. R. Foucault leitor de Kant. In: Passagens. Estudos sobre a filosofia de Kant, Rio de Janeiro, UFRJ, 2003.

TODOROV, T. O espírito das Luzes. Tradução de Mônica Cristina Côrrea. São Paulo, Barcarolla, 2008.

TORRES FILHO, R. R., À sombra do Iluminismo. In: Ensaios de filosofia ilustrada. São Paulo, Iluminuras, 2004.

VOLTAIRE, Cartas inglesas ou Cartas filosóficas. Tradução de Marilena de Souza Chauí Berlinck. São Paulo, Col. Pensadores, Abril, 1973. 